\title{
AMERICANISMO E EDUCAÇÃO um ensaio no espelho
}

\author{
Mirian Jorge Warde \\ Professora e Coordenadora do Programa de Estudos Pós-Graduados em Educação: História, Política, Sociedade da PUC-SP
}

\begin{abstract}
Resumo: O artigo tem como questão principal como e por que, a partir de meados do século XIX, os Estados Unidos representam um espelho no qual o Brasil deveria se mirar. Sem suspender as especulações em torno do que o Velho Mundo poderia oferecer ao nosso futuro, a cultura norte-americana se apresenta como o melhor dos horizontes possíveis, porque além de ser a expressão de uma sociedade que constrói a sua própria identidade, oferece a todos as chances de uma vida de progresso e democracia. Ao mesmo tempo, porém, que passamos a alimentar o imaginário de um dia construirmos em nosso país o laborioso homem norte-americano, desenvolvemos, por outro lado, a nossa imagem como feia e atrasada.

Palavras-chave: americanismo; homem novo; educação.
\end{abstract}

$\mathrm{E}$ ste artigo é um desdobramento dos estudos regulares sobre educação no período que vai de meados do século XIX às primeiras décadas deste século, com a atenção voltada, especialmente, ao processo de inserção da escola nos intentos de construção da modernidade no Brasil. Em incursões de pesquisa, foram registrados deslocamentos discursivos que vão se dando mediante a passagem do foco do "regime de governo" para o "sujeito" ou o "homem novo" necessário à modernidade.

Mais recentemente, foram retomados os antigos ensaios do e sobre o período e outras peças documentais que levam a pensar num outro deslocamento chamado metaforicamente de "troca de espelhos".

São deslocamentos ora flagrantes ora sutis, ora conflituosos ora pacíficos em que nunca se deixou de fazer referência ao Velho Mundo como fonte de uma cultura na qual os brasileiros deveriam incessantemente se banhar caso quisessem conquistar o status de civilizados, mas os Estados Unidos vão se afigurando nos ensaios utópicos das elites intelectuais e no imaginário social como a terra prometida, sem as mazelas da Europa envelhecida e conflituosa.

Desde a Proclamação da Independência política do Brasil do jugo português, em 1822, a representação de um Brasil como parte constitutiva da América Latina não compôs o imaginário nacional; os projetos de construção da identidade e unidade nacional foram alimentados por referências ao mundo extracontinental; a Europa e depois os Es- tados Unidos cedo constituíram o espelho onde o Brasil tinha de se mirar, e não os "pares" latino-americanos. É provável que não tenhamos levado suficientemente a sério as lucubrações geo-ideológicas da França de Napoleão III, que quase quatro séculos após a descoberta das Índias Ocidentais, para conferir uma suposta unidade lingüística, cultural e "racial" dos povos latinos, em contraposição aos germânicos, anglo-saxões e eslavos, resolveu inventar a expressão “América Latina” (Morse, 1988:14).

A partir de meados do século XIX, portanto duas a três décadas somente após a declaração da independência, começaram a circular no Brasil, particularmente nos e a partir dos centros urbanos do Sudeste (São Paulo, em especial), teses segundo as quais as chances do Brasil trilhar o caminho do progresso estavam em se espelhar não mais no Velho Mundo, mas no Novo Mundo, ou seja, nos Estados Unidos.

Mas, o que do Novo Mundo era preciso extrair para que a civilização e a modernidade pudessem ser plantadas na terra brasilis? É isso exatamente o que se busca e, supõese, permitirá flagrar alguns dos elementos que passaram a alimentar o imaginário nacional sobre o passado brasileiro, para que possa ser organizada a cozinha do futuro.

Antes de serem apresentados os argumentos e exatamente para torná-los inteligíveis, apresentamos dois comentários preliminares. Em primeiro lugar, ao se vasculhar a chamada historiografia brasileira do século XIX e início 
do século XX, constatou-se que o uso da expressão "América Latina" ocorre sempre que é preciso afirmar que o Brasil faz parte do continente sul-americano, portanto para afirmar a inserção geográfica do Brasil num continente que se situa na parte sul das Américas. Esse uso reporta-se diretamente à afirmação de que o Brasil não faz parte da América do Norte, mais do que a afirmação de que ele faz parte de uma outra América. No Brasil, usam-se livremente os termos "americano" e "americana" para se referir ao que é dos Estados Unidos. Nas traduções de impressos oriundos dos Estados Unidos ou da Europa esses termos não são alterados, isto é, adota-se a metonímia pela qual a parte se identifica com o todo (fórmula recentemente adotada por Renato Janine Ribeiro em debate na grande imprensa).

Foi feita uma consulta mais ou menos ampla sobre as possibilidades lingüísticas oferecidas pelo idioma português praticado no Brasil para se referir ao que é, originase ou está nos Estados Unidos e a conclusão foi pela inexistência de um termo que substitua, com força, os termos usuais: "americano", "americanismo" e assemelhados.

Em segundo lugar, trabalhou-se com os termos "espelho", "espelhar" e correlatos, uma metáfora retirada de um dos grandes estudiosos da história cultural brasileira, Richard Morse, um "americano" que por anos dedicouse a estudar a América Latina e de forma muito particular o Brasil, onde residiu por certo tempo. Morse publicou em 1988 um livro com o título Prospero's mirror: a study in new world dialetic, já traduzido no Brasil. Em seu prefácio, o autor explica os termos próspero e "espelho", e é este último que nos interessa. Diz ele: "É sabido que um espelho dá uma imagem invertida. Embora as Américas do Norte e do Sul se alimentem de fontes da civilização ocidental que são familiares a ambas, seus legados específicos correspondem a um anverso e um reverso. Assim, a metáfora do espelho parece apropriada ao caso. Em suas vidas domésticas os seres humanos aceitam rotineiramente a inversão do espelho, quando fazem a barba sem se cortar ou aplicam cosméticos sem deixar manchas. Em sua vida nacional coletiva, porém, sentem mais dificuldade de realizar a transposição" (Morse, 1988:13).

Apesar da dificuldade, a metáfora é profícua.

\section{O IMAGINÁRIO SOCIAL TEM UMA LÓGICA PECULIAR}

Em 1914, o então prefeito da cidade de São Paulo declarava em seu relatório oficial que a cidade estava se aparelhando para ser um grande centro industrial, alguma coi- sa como Chicago e Manchester juntas. A referência a Manchester seria em breve abandonada, da mesma maneira que os débitos com a Inglaterra iam sendo esquecidos, junto com os juros dos empréstimos jamais saldados. Mas ficou Chicago como referência. Lá pela década de 50 era comum encontrar nos bondes que circulavam por São Paulo a frase: "São Paulo, a Chicago da América do Sul" (Ortiz, 1990 e Morse, 1988). Não havia na cidade mais do que "três ou quatro prédios com cem anos de idade"; a arquitetura de São Paulo já era no mínimo caótica, em que se misturavam o colonial, a art nouveau, o moderno e tudo o mais que carecia de estilo. Assim, é provável que a analogia daquele antigo prefeito fizesse algum sentido no que se referia aos percursos efetuados pelas duas cidades entre meados do século XIX até as primeiras décadas do século XX. Nos anos 50, a analogia já havia se tornado um tanto forçada; de Chicago, talvez, o que São Paulo guardava de mais próximo era a sua escola de estudos sociológicos, composta de um número grande de acadêmicos que absorveram, através dos seus mentores americanos sediados no Brasil ou de viagens de estudos, o padrão das pesquisas empíricas da Universidade de Chicago.

Mas as iniciativas de espelhar o Brasil nos Estados Unidos antecedem o prefeito ufanista. Pouco tempo depois de proclamada a Independência do Brasil e instituído o regime monárquico, em 1822, começaram a circular projetos de organização do Estado, ora associando-o ao regime republicano, ora vinculando-o à definição de fronteiras, ora postulando a necessidade de se produzir o povo brasileiro para que dele brotasse a nação. Qualquer desses projetos remetia a algum modelo imaginado como vitorioso, bem-sucedido.

Seguramente, no Brasil, como em boa parte do mundo ocidental, a França alimentou utopias políticas e projetos de modernidade. No Brasil, ela já vinha servindo de referência desde as últimas décadas dos setecentos; dos brados de liberdade à sofisticação da belle époque, da moda à organização disciplinar do ensino médio; é com Paris que a intelectualidade brasileira e os socialmente emergentes aprendiam a adquirir lustro e tornar menos enfadonhos os seus dias provincianos. Mas foi com a própria França napoleônica e suas erupções regressivas que aquelas elites brasileiras começaram a assimilar a crença de que elementos da utopia revolucionária e modernizadora francesa estavam sendo realizados não lá, muito menos no resto da Europa, mas basicamente nos Estados Unidos. A viagem de Tocqueville aos Estados Unidos em 1831 é emblemática. Ele arranjou uma desculpa para a viagem, 
mas, em verdade, foi movido pelas inquietações que fervilhavam na França quanto aos rumos que a utopia democrática tomava naquele país, ao mesmo tempo que foi cotejá-la com o outro lado do Atlântico. Dessa viagem, sabidamente resultou a obra A democracia na América.

Mas, retornando ao Brasil, quaisquer que fossem os projetos nacionais ou as imagens de nação em circulação, para todos os lados as possibilidades de construí-la esbarravam na questão da construção do povo brasileiro como condição mesma da nação. Essa era a questão mais presente nos ensaios de pensar o Brasil, que vai alimentando o imaginário social. $\mathrm{O}$ que estava em jogo era o que Todorov chamaria de a questão entre "nós" e "os outros", enfrentada a partir da periferia do Império Ocidental (Todorov, 1993a e 1993b).

Em 1835, portanto, 13 anos após a independência brasileira do jugo português, um jornal que circulava na cidade de São Paulo, O novo farol paulistano, publicava em editorial: "Quanto mais attento para o Brasil, mais me convenço de que não está preparado para a republica. Todos reconhecem que esta forma de Governo, onde o povo é tudo, exige, para se manter, que o mesmo seja proporcionalmente instruído; e tenha muita morigeração, muito amor ao trabalho, finalmente muitas virtudes. E está por acaso n'estas circunstancias a população do Brasil? ... Não macaqueemos os Estados Anglo-Americanos, que tiverão outros princípios, outra educação, outro regimen: sim, os EstadosUnidos forão povoados e educados por Filosofos; o Brazil por criminosos profugos e degredados. Os Estados-Unidos começarão logo com a Constituição Ingleza; o Brasil com as barbaras e goticas Instituições de Portugal, com a Ordenação do Livro 5o- \&c. Os Estados-Unidos tiverão, desd'o seu começo, suas Assembleias Provinciaes, e forão criados com o leite da Liberdade; o Brasil estabeleceo-se sob o mais duro regimen colonial, nem conheceo outros direitos senão os caprichos de seus Verres, chamados Capitães Generaes, e a trapaça do Foro. Nos Estados-Unidos introduzio-se logo o trabalho e a industria; no Brasil a calaçaria e fausto dos mandões" (apud Morse, 1988:91-92).

Ao Brasil, então, faltava povo, pois que esse se faz com instrução, trabalho e muitas virtudes. Porque faltaram filósofos, diz o nosso editorialista, filósofos que nos tivessem dado princípios e educação. Aí estava todo o abismo que nos separava! Além disso, o ponto de partida dos Estados Unidos fora a Constituição Inglesa, desde o início tiveram Assembléias Provinciais e beberam da fonte da Liberdade. Por fim, começaram pelo trabalho e pela indústria. E o Brasil, foi fadado a quê? A ser povoado por profugos e degredados; ser organizado pelas Ordenações portuguesas bárbaras e góticas; nosso regime foi o mais duro colonialismo, com mandonismos, caprichos e trapaças dos todo-poderosos. Em lugar de trabalho e indústria, calaçaria e fausto.

Essa fala é paradigmática; nela, estão contidos praticamente todos os elementos que alimentarão o imaginário de que no Novo Mundo do Norte instaurava-se a terra prometida, mas também a descrença de que pudéssemos atingila, por vício de origem. Nosso pecado era original!

Uns tantos anos depois, em 1869, o jovem engenheiro Paula Souza, que fora aperfeiçoar-se nos Estados Unidos e acabou por trabalhar nesse país temporariamente, envia uma carta de Chillicothe, Missouri, para um amigo no Brasil, em que expressa seu entusiasmo com o padrão de educação que ele observava: "Nós, míseros cidadãos brasileiros, não temos idéa, nem podemos ter, do immenso apreço em que o yankee tem a eschola. É uma das principaes, sinão a principal questão, do condado, da cidade. Os homens mais activos e conceituados são eleitos para fazer parte do conselho de educação (...) É que a educação é para o americano do norte como a carne e o pão de que necessitam todos os dias. Por isso é também o povo o mais instruído, o mais activo, o mais livre e o mais poderoso do mundo.

Pudéssemos nós imitá-lo! Pudéssemos esquecer as velhas e corruptas fórmulas a que vivemos subjugados, olvidando-nos de que vivemos também no continente americano!" (Sousa apud Morse, 1970:188).

A situação era grave: os brasileiros, apegados aos prazeres do corpo, subjugados pela corrupção, inautênticos, não podiam nem imaginar o que era viver da espiritualidade! Em contraste com os brasileiros, a representação popular descentralizada, a escola disseminada, o povo industrioso, livre, honesto, enfim, americanos autênticos. Nem mimesis podia nos salvar! Espelho perverso, nele nos víamos não só invertidos, mas deformados. No imaginário das elites cravava-se o sentimento de erro e de fracasso.

Sentimento que colidia com a visão paradisíaca que os primeiros viajantes e colonizadores trouxeram para a terra brasilis. Quando aportaram nas novas terras traziam na bagagem a esperança de encontrar a Terra Prometida. Estudiosos da cartografia e das missivas dos navegadores dos primeiros tempos de colonização encontraram claras sobrevivências das representações teológicas medievais para as quais o Paraíso Terreal era acessível; realidade ainda presente em sítio recôndito, mas porventura acessível (Holanda, 1994:IX-X). Nas cartas enviadas aos pa- 
rentes, amigos e aos reis, as menções aos desejos de encontrar a Terra Prometida, o Paraíso Terreste são tão reiteradas quanto o desejo de encontrar o ouro.

"Não admira se, em contraste com o antigo cenário familiar de paisagens decrépitas e homens afanosos, sempre a debater-se contra uma áspera pobreza, a primavera incessante das terras recém-descobertas devesse surgir aos seus primeiros visitantes como uma cópia do Éden. Enquanto no Velho Mundo a natureza avaramente regateava suas dádivas, repartindo-as por estações e só beneficiando os previdentes, os diligentes, os pacientes, no paraíso americano ela se entregava de imediato em sua plenitude, sem a dura necessidade - sinal de imperfeição - de ter de apelar para o trabalho dos homens. Como nos primeiros dias da Criação, tudo aqui era dom de Deus, não era obra do arador, do ceifador e do moleiro.

Dessa espécie de ilusão original, que pode canonizarse a cobiça e banir o labor continuado e monótono, haveriam de partilhar indiferentemente os povoadores de toda a nossa América hispânica, lusitanos, não menos do que castelhanos... Marcando tão vivamente os começos da expansão das nações ibéricas no continente, era inevitável, não obstante, que o mesmo tema paradisíaco chegasse a imprimir traços comuns e duradouros à colonização das várias regiões correspondentes à atual América Latina" (Holanda, 1994:X).

Do paraíso ao inferno? Os brasileiros eram anjos decaídos? Como havia se produzido e disseminado o descrédito, o sentimento de falta e de atraso? Não se tratava apenas de um desacerto quanto ao regime político; por toda a parte, as sociedades se dividiam na busca da forma de organização do governo das coisas e dos homens. Esse não era exatamente o problema, pois as lutas políticas e as saídas políticas que as sociedades apresentavam eram a expressão mesma do que elas eram e podiam ser; se cada sociedade é a medida das suas próprias possibilidades, então cabia avaliar se a sociedade brasileira era constituída de seres que suportariam a sua própria utopia. Para Baczko (1984:7), esse seria o grande dilema político e social da modernidade: "comment imaginer et penser la société comme auto-instituée, ayant la pleine maîtrise de soi et ne reposant sur aucun ordre extérieur à elle-même?".

\section{ESPELHO, ESPELHO MEU...}

São inúmeros os relatos de viajantes estrangeiros que penetraram no território brasileiro entre fins dos séculos XVIII e o século seguinte para esquadrinhar fauna, flora, minerais, recursos hídricos... Nesses relatos, aqueles viajantes em missões ditas científicas demarcaram com toda a nitidez a grandiosidade da natureza em contraposição à pequenez humana. Tudo o que permanecia tal qual saído das mãos do criador era imponente, rico, dadivoso; o que eles viram como produto da ação humana era feio, sujo, insalubre, incivilizado...

Foi dessa forma que as representações brasileiras compareceram às Exposições Internacionais. Inauguradas em 1851, em Londres, estendendo-se com regularidade até as primeiras décadas do século XX, as Exposições Internacionais produziram e foram produzidas como expressão acabada da civilização moderna. Funcionaram como espelhos mediante os quais as nações podiam olharse, olhando as demais. Eram "festas didáticas" (Kuhlmann Jr., 1996) e carregavam o método de constituição das nações. Ensinavam que criar uma nação exige comparação. Essa regra de método passa também a alimentar os imaginários sociais (Turazzi, 1995).

Marx e Engels denominaram a Primeira Exposição de 1851, em Londres, de Panteão da moderna Roma, onde a burguesia exibia seus deuses!

Na Exposição de Paris de 1889, o guia publicado para orientar os visitantes do evento explicava aos potenciais visitantes: "Com que espírito é preciso visitar a Exposição? É preciso vê-la com o mesmo espírito que presidiu a sua organização: é preciso vê-la para se instruir e para se divertir. Ela é para todo mundo, para todas as idades, para os sábios, assim como para os menos instruídos, uma incomparável 'lição de coisas'. O industrial aí encontra os modelos dos quais ele saberá aproveitar. O simples passante aí toma uma idéia geral e suficiente das maravilhas, sempre em progresso, da indústria moderna. Um pode aí encontrar o caminho da fortuna, pelo estudo dos processos aperfeiçoados de fabricação; outro aí encontra, com os objetos usuais colocados sob seus olhos, a satisfação econômica do seu gosto" (apud Pesavento, 1997:13.)

Benjamin (1975) viu as Exposições como "lugares de peregrinação ao fetiche que é a mercadoria". Michelle Perrot as estudou como "...grande espetáculo que o capitalismo oferece ao mundo, essa 'vitrine' gigantesca que celebra as maravilhas da Indústria e das Fábricas, catedrais da nova humanidade, desempenharam um papel decisivo na formação de uma mentalidade técnica e na difusão de uma ideologia da Ciência e do Progresso" (Perrot, 1988:91).

Ensinavam, festivamente, a ciência de se exibir, a pedagogia de se mostrar e a didática de bem-ver. Deixar-se ver e ver; essa era a via de construir compositamente a 
identidade e a alteridade das nações. Em obra publicada por ocasião da participação do Brasil na Exposição de Paris de 1889, diz o autor: "As exposições universais, que foram tão criticadas, têm pelo menos a vantagem incontestável de permitir aos diferentes Estados que aí tomam parte estabelecer uma espécie de balanço oficial para a maior parte dos ramos de sua produção. Quão rico ou quão pobre que seja, é sempre útil conhecer exatamente o ponto de prosperidade ou de decadência em que se acha. Para isso, é suficiente aos indivíduos colocar em linha de conta o seu ativo e o seu passivo. Não se passa assim da mesma forma quando se trata dos povos. A fim de apreciar (...) seu estado econômico, é preciso dizer que eles o comparem a aquele de seus vizinhos, porque, na luta internacional do comércio e da indústria, tudo não é senão negócio de relações" (Nery, 1889 apud Pesavento 1997:13).

Comparar e classificar, esse era o método na sua integralidade. A exposição de 1876, realizada na Filadélfia, comemorativa da Independência dos Estados Unidos, é considerada paradigmática nas regras da classificação; o responsável pela distribuição dos produtos - William P. Blake, geólogo e engenheiro de minas - fixou dez, depois oito grupos, divididos em 350 classes. A proposta de Blake era "colocar as matérias-primas como primeiro degrau do progresso, e assim sucessivamente até apresentar, no final, as mais altas conquistas do intelecto e da imaginação". Nessas exposições, os países aprendiam a organizar os seus registros educacionais, a fazer relatórios minuciosos, a elaborar estatísticas, a apresentar novos dispositivos, tecnologias e métodos de ensino. O alcance ordenador desse sistema classificatório foi grande (Mevil Dewey teria usado o sistema de Blake como base para sua classificação decimal na organização dos livros nas bibliotecas públicas).

E lá estava o Brasil, no concerto das nações, com seus stands de produtos naturais: café, madeiras, minérios, plantas exóticas, e com o folclore de seus negros e índios. Mas, através dos seus representantes oficiais, pronto a encomendar lotes de cadeiras ergométricas, aparelhos para estudos de frenologia, criminalística, antropometria e... e cartilhas para alfabetização das crianças.

Assim, através das suas elites políticas e intelectualizadas, os brasileiros aprendiam a "introjetar" (o verbo é intencional) sua identidade: olhando no espelho, representavam-se pelos olhos dos "outros". O que viam era invertido, mas não era mais deformado; era feio mesmo. O número de 27/5/ 1876 da Harper's Bazar, dedicado à Exposição Internacional de Filadélfia, apresenta uma caricatura do então imperador brasileiro, D. Pedro II, ladeado por brasileiros com ca- beça de animal (burros e gansos), acompanhada de uma legenda depreciativa: "Do give the good man a chance!".

\section{COMPARAR, CLASSIFICAR E EVOLUIR...}

As Exposições Internacionais desempenharam papel fundamental na difusão e "confirmação" das teses evolucionistas. Ali, mostravam-se, ordenadamente, as diferentes fases pelas quais a humanidade havia passado. E para os modernos que jamais poderiam acessar seus antecedentes primitivos, o Brasil oferecia exemplares do homem primitivo. Aliás, cada país apresentava-se sob a forma de protótipos: de máquinas, de produtos, de tecnologias, de plantas, de animais, de seres humanos. Tudo devidamente selecionado e classificado. Uns compareciam com mais materialidade do que outros, que se apresentavam com mais espiritualidade; uns vinham com mais natureza, outros com mais cultura; uns com gente, outros com coisas. Mas cada um ao seu jeito compunha o concerto hierarquizado segundo as leis da evolução que se apresentava como expressão de um vetor único do progresso: a máquina.

No Brasil, as teorias evolucionistas, positivistas, darwinistas começaram a circular contemporaneamente e através das Exposições Internacionais. Misturaram-se nas mentes das elites intelectuais, mas não circularam apenas entre elas. Especialmente o positivismo e o evolucionismo spenceriano circularam amplamente e penetraram no imaginário social; serviram de lente, ou se quisermos de crivo mediante o qual as teses de cientificismo e racionalização da cultura foram lidas, interpretadas e assimiladas em fins do século XIX e primeiras décadas do século XX.

A menção aos aparelhos de psicometria, antropometria e criminalística serve tão-somente para indiciar que na segunda metade do século XIX as teorias racistas passaram a circular no Brasil, alimentadas pelas sociedades científicas recém-criadas e pelas Faculdades de Medicina e Direito que controlavam com quase absoluta exclusividade a cena cultural do final do século. Mas, não é sobre elas que interessa projetar mais luz, mas sim sobre os dispositivos pedagógicos que são extraídos das idéias de comparação, classificação e evolução.

Em 1904, Oscar Thompson participa da Exposição Internacional de St. Louis. Thompson, de professor primário, chegaria, pouco depois, a Diretor-Geral da Instrução Pública de São Paulo, e visita a Exposição Internacional de onde traz exemplares da cartilha The Arnold Primer, de Sarah Louise Arnold, que ele posteriormente traduz e adapta para a língua portuguesa. Dessa visita, que durara 
muitos meses, Thompson volta absolutamente convencido das enormes vantagens de organizar a formação do magistério nos moldes "americanos" e de aplicar o método de ensino analítico adotado naquele país. Quando se torna Diretor-Geral da Instrução Pública, Thompson converte o método analítico em obrigatório a todas as escolas de São Paulo. Logo depois, o método se difunde por outros estados brasileiros, mediante assessoria de quadros do magistério paulista (Monarcha, 1999).

Qual a hipótese que embala Thompson? O que ancora a difusão das suas crenças para muito além do seu cargo de mando?

Quanto às hipóteses: a ontogênese repete a filogênese; e a organização lógica dos programas de ensino devem seguir a ordem do desenvolvimento do espírito. Nas suas palavras: "Se o método analítico sob o ponto de vista geral e filosófico é o método por excelência, por isso que parte da idéia geral do conjunto - para suas partes, do concreto para o abstrato, do todo - que impressiona claramente a imaginação - para o abstrato, do indizível, que é monótono, árido e insignificativo; não é de estranhar que ele tenha a sua primeira aplicação pedagógica no ensino da leitura, a qual é inquestionavelmente uma operação essencialmente analítica do espírito.

Daí a razão de a escola moderna, essencialmente progressista e científica, preconizar os métodos de ensino indiretos ou naturais, que obedecem em toda sua marcha os mesmos passos seguidos pelo espírito humano na aquisição de conhecimentos" (Thompson, 1910:1-9).

Thompson fazia parte de uma elite de intelectuais que vinha, desde o final do século XIX, postulando a conversão das idéias e métodos da ciência em princípios de organização de um sistema público de ensino, de sorte a pautá-lo nas leis da evolução natural, e mediador entre elas e as exigências de constituição de uma nação. Ou seja, Thompson estava traduzindo para o Brasil aquilo que imaginava ter visto nos Estados Unidos da América: leis da natureza sendo respeitadas, porque convertidas em método de seleção, classificação, diferenciação, ordenação. Ou seja, convertidas em método de intervenção.

Thompson é representativo da nova empolgação republicana: não adiantava continuar chorando as mazelas do passado nem lamentar o povo brasileiro "miscigenado". Era preciso industriosamente intervir. Operar sobre os indivíduos. Durante os últimos anos do século XIX até a década de 20 do século XX, o grupo do qual Thompson fazia parte investiu em muitas frentes para não só constituir o sistema público de ensino paulista e influenciar di- retamente na constituição dos sistemas de ensino em outros estados da federação, como também para difundir a idéia de que a nova ordenação social só seria conquistada se fosse operada a mudança intelectual e moral em cada indivíduo. As crenças de Thompson rebatem o pessimismo do editorialista de 1835 e do engenheiro de 1869. Ele é contemporâneo do prefeito ufanista de 1914: no Brasil, se o maquinista era inferior à máquina, era preciso importar a máquina e adaptar o maquinista a ela.

Essas últimas considerações são propositadamente gramscianas, pois, através delas, evidencia-se que se está pensando o "americanismo" com débito especial ao legado conceitual gramsciano.

Embora Gramsci tenha deixado registrados em vários pontos dos seus Cadernos ensaios interpretativos sobre o papel que os Estados Unidos vinha ocupando na configuração de novos padrões de cultura, ou como ele preferiria dizer, novos padrões intelectuais e morais, é sabidamente nos apontamentos sobre o Americanismo e Fordismo ${ }^{1}$ que se encontram as idéias mais sistematizadas sobre $o$ assunto.

O que de central Gramsci oferece como base preliminar para se pensar o americanismo diz respeito, de um lado, ao fato de que ele de maneira absolutamente original e contrariando leituras prevalecentes apreendeu o americanismo como o fenômeno de maior envergadura no momento pelo qual o capitalismo estava passando, ou seja, Gramsci viu no americanismo um acontecimento "supraestrutural", melhor dizendo um acontecimento de mudança radical de toda uma cultura cujo peso jamais poderia ser minimizado, posto que exercia a função de cimentar as reformas econômicas em curso (diria ele, o nome da reforma econômica é reforma intelectual e moral); de outro lado, Gramsci viu nessa cultura a operação de recriação do sujeito; ou seja, nos termos da época, o americanismo estava produzindo um "homem novo". E a eficácia do americanismo era devida, e muito, às condições históricas diferençadas dos Estados Unidos que não precisavam carregar como camada de chumbo as velhas tradições européias (culturais, demográficas, políticas, estatais, etc., etc.); mas devia-se antes de mais nada ao fato de que o americanismo era a filosofia que se afirmava na ação; tão poderosamente afirmada na ação que estava conseguindo produzir uma nova conformação psicofísica, estava inventando um "homem novo" (Gramsci, 1978:375-413).

Foi essa genial (pre)visão que Gramsci enunciou sobre o americanismo que o fez capaz de entender que o pragmatismo não era uma tola e menor filosofia do senso comum, despre- 
zível em face da longa tradição da filosofia européia, nem da suposta superioridade "práxica" do marxismo. Para Gramsci (1978: 401), o pragmatismo era a única filosofia cuja eficácia prática media-se pelo grau de adesão/convencimento que conquistava. Tratava-se de convencimento não no "vocabulário", mas de convencimento na "ação". Não é também casual que Gramsci (1999) tenha centrado suas energias críticas em Croce, ou seja, no pragmatismo croceano.

Cabe reforçar, também, que Gramsci ajuda a pensar o americanismo como "mudanças do modo de ser e viver", e como tal é processo de configuração subjetiva. Aí está um elemento fundamental sobre o qual o projeto se encaminha: o americanismo como processo educacional, ao mesmo tempo que fez da educação o seu apanágio. O que pretende-se verificar é como, através de que mecanismos - discursivos e não-discursivos - o americanismo penetrou no Brasil e constituiu-se em cultura, moldou formas de pensar, sentir e viver; tornou-se parâmetro de progresso, felicidade, bem-estar, democracia, civilização; de que modo o americanismo moldou as esperanças em torno da cidade e da indústria, projetou padrões de arquitetura; redimensionou espaços e acelerou os tempos; plantou nos corações e nas mentes a silhueta do "homem novo" - racional, administrado e industrioso.

\section{COMENTÁRIO FINAL}

Destaca-se, ao término desta exposição, que se preferiu trabalhar com indícios para construir os argumentos. Ou seja, não houve interesse nos fatos pirotécnicos que poderiam servir de prova inconteste e universal de uma tese. Assim, há a disposição em se pensar a reconstrução de um imaginário social, supondo-se que ele tenha sido constituído de uma vez para sempre e seus elementos constituintes fossem necessariamente mitos, símbolos, alegorias, ideologias coerentes e exclusivas. Ao contrário, a pesquisa desenvolve-se sobre o "americanismo e educação" a partir de elementos mais discretos, menos dramáticos, que permitem verificar como foi sendo produzido o convencimento que o Brasil - atrasado, faltoso, errado no seu itinerário - poderia passar para o moderno, o civilizado, pela intervenção da educação e da maquinaria.

Para trabalhar com o imaginário como âncora para a difusão do americanismo, Bronislaw Baczko, autor referido anteriormente, oferece poderosas ferramentas. Ele tem feito pensar que as elites políticas se dão conta muito rapidamente de que o dispositivo simbólico constitui um instrumento eficaz para influenciar e orientar a sensibilidade coletiva e para manipulá-la. Mirabeau, com sua intuição política habitual, dizia à época da Revolução Francesa, que não basta "mostrar a verdade: o ponto fundamental é fazer com que o povo a ame", é necessário apoderar-se da sua imaginação. O ponto fundamental para Mirabeau era o que ele denominava de "formação das almas" (Baczko, 1984: 53; na mesma direção Carvalho, 1990).

\section{NOTAS}

E-mail da autora: warde123@pucsp.br

1. Gramsci, nos apontamentos sobre o Americanismo e Fordismo, utiliza freqüentemente o primeiro termo associado ao segundo, o que se explica no contexto em que ele está discutindo a questão. Sem distorcer a perspectiva gramsciana, utiliza-se aqui americanismo no sentido amplo que ele confere e por isso mesmo passível de ser mencionado sem o complemento do fordismo; ou seja, o americanismo contém o fordismo; embora o fordismo tenha sido indispensável para a construção e difusão do americanismo, este antecede aquele e o extravasa.

\section{REFERÊNCIAS BIBLIOGRÁFICAS}

BACZKO, B. Les imaginaires sociaux: mémories et espoirs collectifs. Paris, Payot, 1984.

BENJAMIN, W. "Sobre alguns temas em Baudelaire". A modernidade e os modernos. Rio de Janeiro, Tempo Brasileiro, 1975.

CARVALHO, J.M. de. A formação das almas: o imaginário da República no Brasil. São Paulo, Companhia das Letras, 1990.

GRAMSCI, A. Maquiavel, a política e o Estado moderno. Rio de Janeiro, Civilização Brasileira, 1978. Cadernos do cárcere. Rio de Janeiro, Civilização Brasileira, v.1, 1999.

HOLANDA, S.B. Visão do paraíso: os motivos edênicos no descobrimento e colonização do Brasil. São Paulo, Brasiliense, 1994.

KUHLMANN Jr., M. As grandes festas didáticas: a educação brasileira e as exposições internacionais (1862-1922). Tese de Doutorado. São Paulo, USP, 1996.

MONARCHA, C. Escola Normal da Praça: o lado noturno das luzes. São Paulo, Ed. Unicamp, 1999.

MORSE, R. O espelho de Próspero: cultura e idéias nas Américas. São Paulo, Companhia das Letras, 1988.

. Formação histórica de São Paulo. São Paulo, Difusão Européia do Livro, 1970 .

ORTIZ, R. "Notas sobre as ciências sociais no Brasil". Novos Estudos Cebrap. n.27, julho 1990, p.163-175.

PERROT, M. Os excluídos da História: operários, mulheres, prisioneiros. Rio de Janeiro, Paz e Terra, 1988.

PESAVENTO, S.J. Exposições universais: espetáculos da modernidade do século XIX. São Paulo, Hucitec, 1997.

SCHWARCZ, L.M. O espetáculo das raças: cientistas, instituições e questão racial no Brasil 1870-1930. São Paulo, Companhia das Letras, 1993.

THOMPSON, O. "Relatório apresentado ao Exmo. Sr. Dr. Secretário do Interior". Annumario do Ensino do Estado de São Paulo: 1909-1910. São Paulo, Typographia do "Diario Official", 1910.

TOCQUEVILlE, A. de. A democracia na América. São Paulo, Martins Fontes, 1998.

TODOROV, T. Nós e os outros: a reflexão francesa sobre a diversidade huma$n a-I$. Rio de Janeiro, Jorge Zahar, 1993a.

A conquista da América: a questão do outro. São Paulo, Martins Fontes, 1993b.

TURAZZI, M.I. Poses e trejeitos: a fotografia e as exposições na era do espetáculo (1839-1889). Rio de Janeiro, Funarte/Rocco, 1995. 